\section{International classification of function, disability and health framework for fall risk stratification in community dwelling older adults}

Majumi M. Noohu, ${ }^{1}$ Aparajit B. Dey, ${ }^{2}$ Shashi Sharma, ${ }^{3}$ Mohammed E. Hussain ${ }^{1}$

${ }^{1}$ Centre for Physiotherapy and

Rehabilitation Sciences, Jamia Millia

Islamia, New Delhi; ${ }^{2}$ Department of

Geriatric Medicine, All India Institute of

Medical Sciences, New Delhi; ${ }^{3}$ Institute

of Cytology \& Preventive Oncology,

Sector - 39, Noida, Uttar Pradesh, India

\section{Abstract}

Falls is an important cause for mortality and morbidity in older adults. The fall risk assessment is an integral component of fall prevention in older adults. The international classification of function, disability and health (ICF) can be an ideal comprehensive model for fall risk assessment. There is lack of information relating ICF and fall risk assessment in community dwelling older adults. In this study we tried to assess the fall risk using different domains of ICF using various clinical tools.

A total of 255 subjects were recruited through convenient sampling method from geriatric clinic (OPD) of All India Institute of Medical Sciences, New Delhi. The study was single session cross-section design. The body mass index (BMI), grip strength, depression score (Geriatric depression scale:short form; GDS-S) and co morbidities were used to assess body function and structure domain, timed up and go (TUG), Berg balance scale (BBS) and elderly fall screening test (EFST) scores were used for activity domain, selfreported cause of fall, medications and uses of assistive device for environmental factors. Then the association of body function and structure, activity and environmental factors were determined with falls.

There was an association of fall in analysis in subjects with no fall and one or more falls for, BMI, grip strength (kg), GDS-S score, no. of co morbidities, chronic pain, TUG, BBS, TUG (s), BBS, EFST, slip/trip, walking cane, hypoglycemic and antihypertensives medications (unadjusted and adjusted odds ratio). The diabetes, and hyper tension showed association for adjusted odds ratio only. In subjects with one fall and more than one fall, TUG, BBS, EFST, GDS-S score, NSAIDS and antidepressants use showed a significant association with fall (unadjusted and adjusted odds ratio).

The ICF may be used in routine for fall risk assessment in community dwelling older adults.

\section{Introduction}

Falls in elderly of age group between 65 to 75 and above range from 28 to 42 percentage in different parts of the world. There is no epidemiological data available for falls in south Asian population and only limited published data is available for identification of risk factors for falls in above mentioned population. $^{1-3}$ The falls may result in fractures, fear of falling, hospital admissions and poor quality of life. Post fall syndrome, characterized by dependence, immobilization, depression, and restrictions in daily activities may be an outcome of fall. Fall can even cause death and 40 percentage of death related to injury is attributed to falls. The major risk factors identified for falls in older adults are age, previous history of falls, reduced lower limb muscle strength, medications and balance disorders. ${ }^{4-10}$

A fall is identified as one of the external causes of unintentional injury by World Health Organization (WHO). According to International Classification of Disease-9 (ICD-9), it is coded as E880-E888 and W00W19 in ICD-10. ${ }^{1}$ The WHO in 2001, adopted the International Classification of Functioning, Disability and Health (ICF), as a framework for measuring health and disability. It is a classification system for the description of health at both individual and population levels. It assesses the health status at three levels: impairment (body structures and function), activity limitation and participation restriction. It takes into account of contextual factors of the environment and personal factors also. According to ICF the positive aspect of health is referred as functioning and the negative aspect as disability. ${ }^{11,12}$ The ICF which has 1424 categories can be an ideal comprehensive model for fall risk assessment. But the large number of categories in the model makes it difficult to use in clinical practice. So the ICF core sets were developed for specific diseases to make it more clinical friendly. The ICF core set was developed and found that, it can be used to assess fall risk in acute rehabilitation settings. ${ }^{13,14}$ The fall risk assessment is an integral component of fall prevention programme in older adults. ${ }^{15}$

There is a lack of information relating ICF and fall risk assessment in community dwelling older adults. In this study we tried to assess the fall risk using different domains of ICF using various clinical tools.
Correspondence: Mohammad E. Hussain,

Centre for Physiotherapy and Rehabilitation Sciences, Jamia Millia Islamia, New Delhi110025, India.

Tel.: +91.11.26981717;

Fax: +91.11.26980229.

E-mail: ehusain@jmi.ac.in

Key words: Falls; balance impairment; fall screening; morbidity.

Acknowledgments: we would like to extend our thanks to Jamal Ali Moiz, Assistant Professor and all the supporting staff of Centre for Physiotherapy and Rehabilitation Sciences Jamia Millia Islamia, New Delhi.

Received for publication: 28 December 2016. Revision received: 21 March 2017.

Accepted for publication: 7 April 2017.

This work is licensed under a Creative Commons Attribution-NonCommercial 4.0 International License (CC BY-NC 4.0).

CCopyright M.M. Noohu et al., 2017

Licensee PAGEPress, Italy

Geriatric Care 2017; 3:6526

doi:10.4081/gc.2017.6526

The BMI, grip strength, geriatric depression scale:short form score (GDS-S) and co morbidities were used to assess body function and structure domain, TUG, BBS and EFST scores were used for activity domain, self reported cause of fall, medications and uses of assistive device for environmental factors. We used a multi factor assessment as it is recommended for fall screening assessment in older adults.

\section{Materials and Methods}

\section{Sample size and source of subjects}

Assuming the fall rate is $30 \%$ in people above 60 years with variation of $25-35 \%$, a total of 244 subjects were to be enrolled with $\alpha=0.05$. A total of 255 subjects were recruited through convenient sampling method from geriatric clinic (OPD) of All India Institute of Medical Sciences, New Delhi. The subjects included were above 60 years of age, both male and females who were able to ambulate with or without any assistive devices. Subjects with unstable medical conditions, neurological disorders, such as stroke, Parkinson's diseases, multiple sclerosis, non-corrected visual deficits were excluded from the study. An informed consent was signed by each subject before the assessment. It was a cross-sectional single session study design. Each session lasted for 
1 hour. The study was approved by human ethical committee of Jamia Millia Islamia, New Delhi.

\section{Procedure}

The purpose and study details were explained to the subjects who fulfilled the inclusion criteria. Then they signed an informed consent if they were ready to be the part of study. The demographic details of the subjects such as age, gender, height and weight for calculation of body mass index (BMI), co morbidities (diabetes, hypertension, degenerative arthritis, pain) number and type of medicines, number of falls in last 1 year, the nature and self reported cause of fall and whether sustained any injury during falls were also ascertained. The body function and structure domain of ICF was assessed by recording the BMI, grip strength, depression score and co morbidities. The activity domain was assessed by recording mobility (TUG), balance (BBS) and fall screening (EFST). The environmental factors were assessed by recording self-reported cause of fall (slip/trip), number of medicines used and use of walking cane. There was a rest period of 3 to 5 minutes between each test. An assistant was there with subjects to prevent falls during TUG, BBS and EFST tests.

\section{Recording/measurement of variables}

Fall

The fall and number of falls in last one year was recorded by asking the subject to recall any incident or number of times in which he happened to be in ground or to a lower level while walking or during change in body position. ${ }^{16}$

\section{Body mass index}

The subject's body weight and height was recorded first. Total body weight was measured using a standardized weighing machine. The subject had to stand straight with looking forward on a weighing machine without carrying any object for measuring body weight. Body Weight was recorded in kilograms $(\mathrm{kg})$. For standing height the subject stood straight with shoes off against a stadiometer fixed on a wall. They had to stretch upward, take and hold a full breath, while the ruler was lowered till it touched the vertex firmly. This marking was taken as standing height and recorded in centimeters $(\mathrm{cm})$. Then the BMI was calculated by the equation: ${ }^{17}$

BMI=Weight $(\mathrm{kg}) /[\text { Height }(\mathrm{m})]^{2}$

\section{Grip strength measurement}

The grip strength was measured using the subjects in standing position slightly bend forward. The elbow was in extended position with slight flexion at shoulder joint. The subjects were asked to perform 3 trials on both the hands and sum of the best trail was recorded as the hand grip strength. ${ }^{18,19}$

\section{Co morbidities}

The number and type of comordities were collected by interview of the subject and from medical records. The comorbidities checked were diabetes, hypertension, degenerative joint diseases, pain in lower extremity.

\section{Screening of depression}

Geriatric depression scale short form was used to screen subject for presence of depression. The GDS-S is a 15 -item scale. The interviewer asked the questions in the scale to the subject they had to give a yes or no response to the question. Each yes answer is given 1 point and no is given 0 . If a subject scored more than 5 point they were excluded from the study. ${ }^{20}$

\section{Measurement of TUG score}

TUG is a functional mobility scale developed by, Podisasdlo et al. The sensitivity and specificity of this scale for identifying fallers were established by, Shumway-Cook, et al. For recording TUG scores the subjects sat on a standard chair with arm rest and the subjects had to get up from the chair, walk pre-marked distance of 3 meters, turn around and come back and sit again on the chair. The whole activity was timed using a stopwatch and the time taken to complete the activity is TUG score. The activity was done thrice and average of 3 readings was taken. ${ }^{21,22}$

\section{Administration of BBS}

BBS is a 14 item balance assessment tool in which subjects were asked to perform activities, such as: i) sit to stand; ii) standing unsupported; iii) sitting with back unsupported with feet on floor or on a stool; iv) stand to sit; v) transfers; vi) standing unsupported with eyes closed; vii) stand unsupported with feet together; viii) reaching forward with outstretched arm; ix) pick up object from the floor from a standing position; $x$ ) turn to look behind over left and right shoulders while standing; xi) turn 360 ; xii) place alternate foot on bench or stool while standing unsupported; xiii) stand unsupported with one foot in front; xiv) standing on one leg. The scoring is done in a ordinal level for each component with scores from 0 to 4 with maximum score of 56.The BBS has good specificity and sensitivity in identifying fallers and non fallers..$^{23,24}$

\section{Administration of EFST}

The subjects were assessed using EFST. The EFST is a valid tool, which categorizes subjects into different risk levels for falls. The EFST consists of five items divided into two parts in which part one consist of self reported fall history, injury associated with fall or near fall for last one year obtained through the interview and part two consists of observation of gait parameters. The gait parameters were observed by asking the subjects to walk a distance of 5 meters. The time taken to cover the distance and any deviation in gait was observed. History of fall, injury with fall, near fall, if more than $10 \mathrm{~s}$ is taken to cover the $5 \mathrm{~m}$. distance and any unevenness in gait is considered as a positive response. Each positive response is scored as one point. It has a range of 0 (low risk) to 5 (high risk). ${ }^{25}$

\section{Self reported cause of falls (slip/trip)}

The subject was asked to recall the cause of fall. If the subject had a fall due to slip or a trip a score of 1 was given and for any other causes 0 was given.

\section{Number, type of medicines and use of walking cane}

The number and type of medications were collected from medical history by interview of the subject and from medical records. The subjects were asked whether they use walking cane.

\section{Data analysis}

The SPSS software version 21 was used to analyze data by binary logistic regression to determine the association of falls and body structure and function domain, activity domain and environmental factors. The unadjusted and age and sex adjusted odds ratio were calculated for risk of fall for the following variables such as BMI, grip (kg), GDS score, TUG (s), BBS, EFST, no. and type of co morbidities(n), no. and type of medications (n) and use of walking cane. Un- paired t-test was used to find the difference between the age, BMI, grip, TUG, BBS and depression, chi-squred test was used to find the difference between EFST, co morbidities (n), medications (n), slip/trips, injury and number of falls between subjects with one or more falls (fallers) and subjects with no falls (non fallers). The same analysis was carried out for subjects with one fall and subjects with more than one fall. A significance level of $\mathrm{P} \leq 0.05$ was fixed for all the analysis done. 


\section{Results}

The baseline information of the subjects with no falls, one fall and more than one fall is tabulated in Tables 1 and 4.

Out of 255 subjects, 65 (25.49\%) subjects reported one or more falls in which 29 $(11.37 \%)$ subjects had one fall and 36 (14.11\%) had more than one falls. There was 190 subjects [males $=100$, females $=90$ ] without fall, 29 [males $=16$, females $=13$ ] with one fall and 36 [males $=16$, females $=20]$ with more than one fall. The baseline characteristics between the subjects with no fall and one or more falls showed a significant difference for the age [no fall $=70.47 \pm 6.61$, one or more fall $=73.02 \pm 4.33$ ], BMI [no fall $=22.53 \pm 3.39$, one or more fall $=20.78 \pm 2.20]$, grip $(\mathrm{Kg})$ [no fall $=23.98 \pm 6.28$, one or more fall $=12.65$ \pm 2.20 ], TUG (s) [no fall $=12.67 \pm 3.91$, one or more fall $=21.28 \pm 9.07]$, BBS [no fall $=53.21$ \pm 1.91 , one or more fall $=46.77 \pm 7.04]$, depression (GDS-S) [no fall=2.44 \pm 0.86 , one or more fall=2.86 \pm 1.09 ], EFST, co morbidities(n), injury, number of falls, medications, slip/trip, use of walking cane (Table 1).
There was a significant difference between no. of subjects with chronic pain, no. of subjects using hypoglycemics and NSAIDS (Table 2). Where as between the subjects with one fall and more than one fall there was significant difference between grip $(\mathrm{kg})$ [one fall $=17.53 \pm 2.44$, more than 1 fall $=15.05 \pm 1.96$ ], TUG (s) [one fall $=15.83 \pm$ 6.93, more than 1 fall $=25.67+8.22]$, BBS [one fall $=50.52 \pm 5.36$, more than 1 fall= $43.75 \pm 6.83$ ], GDS score [one fall $=2.45 \pm$ 0.50 , more than 1 fall=3.19+1.21], EFST, co morbidities(n), number of falls (Table 4). There was a significant difference between no. of subjects with diabetes, hypertension, chronic pain, lower extremity arthritis, no. of subjects using hypoglycemic, antihypertensives, NSAIDS and antidepressants (Table 5).

The fall risk odds ratio for subjects with no fall and one or more falls showed association for fall with following measures such as, BMI, grip strength (Kg), GDS score, no. of co morbidities, chronic pain, TUG, BBS, TUG (s), BBS, EFST, slip/trip, walking cane, hypoglycemic and antihypertensives medications (unadjusted and adjusted odds ratio). The diabetes, and hyper tension showed association for adjusted odds ratio only (Table 3 ). When the same analysis was done for subjects with one fall and more than one fall, TUG, BBS, EFST, GDS score, NSAIDS and antidepressants use showed a significant association with fall (unadjusted and adjusted odds ratio). While antihypertensive medications showed association for unadjusted odds ratio, no. of co morbidities and no. of medications showed a significant association for falls for adjusted odds ratio (Table 6).

\section{Discussion}

The fall risk analysis for subjects with no fall and one or more fall showed, that there was a association of fall with body function and structure domain (BMI, grip strength, GDS score, no. of co morbidities, diabetes, hypertension, chronic pain), activity domain (TUG, BBS, EFST) and environmental factors (slip/trip, walking cane, hypoglycemic and antihypertensives med-

Table 1. Comparison of baseline characteristics between subjects with no fall and one or more falls.

\begin{tabular}{|c|c|c|c|c|c|}
\hline Variables & & $\begin{array}{l}\text { No fall }(\mathrm{N}=190) \\
(\mathrm{M}=100 ; \mathrm{F}=90) \\
\text { Mean+SD/no. }(\%)\end{array}$ & $\begin{array}{c}\text { One or more falls } \\
(\mathrm{N}=65)(\mathrm{M}=32 ; \mathrm{F}=33) \\
\text { Mean+SD/no. }(\%)\end{array}$ & $t / x^{2}$ & $\mathbf{P}$ \\
\hline Age (yrs) & & $70.47 \pm 6.61$ & $73.02 \pm 4.33$ & -2.89 & 0.004 \\
\hline BMI* & & $22.53 \pm 3.39$ & $20.78 \pm 2.20$ & 3.88 & 0.044 \\
\hline Depression (GDS-S)* & & $2.44 \pm 0.86$ & $2.86 \pm 1.09$ & -3.24 & 0.001 \\
\hline Grip (kg)* & & $23.98 \pm 6.28$ & $12.65 \pm 4.03$ & 13.59 & 0.014 \\
\hline $\operatorname{TUG}(s)^{\circ}$ & & $12.67 \pm 3.91$ & $21.28 \pm 9.07$ & -10.54 & 0.001 \\
\hline $\mathrm{BBS}^{\circ}$ & & $53.21 \pm 1.91$ & $46.77 \pm 7.04$ & 11.4 & 0.001 \\
\hline $\mathrm{EFST}^{\circ}$ & $\begin{array}{l}0 \\
1 \\
2 \\
3\end{array}$ & $\begin{array}{c}116(61.1 \%) \\
64(33.7 \%) \\
10(5.3 \%) \\
-\end{array}$ & $\begin{array}{c}3(4.61 \%) \\
17(26.15 \%) \\
2(44.61 \%) \\
16(24.61 \%)\end{array}$ & 129.72 & 0.001 \\
\hline Comorbidities (n)* & $\begin{array}{l}0 \\
1 \\
2 \\
3 \\
4\end{array}$ & $\begin{array}{c}6(3.2 \%) \\
93(48.9 \%) \\
50(26.3 \%) \\
37(19.5 \%) \\
4(2.1 \%)\end{array}$ & $\begin{array}{c}2(3.07 \%) \\
17(26.15 \%) \\
13(20 \%) \\
21(32.30 \%) \\
12(18.46 \%)\end{array}$ & 39.02 & 0.001 \\
\hline Slip/trip ${ }^{\#}$ & $\begin{array}{l}0 \\
1\end{array}$ & $\begin{array}{c}178(93.6 \%) \\
12(6.3 \%)\end{array}$ & $\begin{array}{l}11(16.92 \%) \\
41(83.07 \%)\end{array}$ & 94.77 & 0.001 \\
\hline Medications (n) ${ }^{\sharp}$ & $\begin{array}{l}1 \\
2\end{array}$ & $\begin{array}{c}135(71.1 \%) \\
55(28.9 \%)\end{array}$ & $\begin{array}{l}47(72.3 \%) \\
18(27.7 \%)\end{array}$ & 39.68 & 0.001 \\
\hline Walking cane $\mathrm{e}^{\#}$ & & $7(3.6 \%)$ & $9(13.84 \%)$ & 8.73 & 0.003 \\
\hline Injury & $\begin{array}{l}0 \\
1\end{array}$ & $\begin{array}{l}00(00 \%) \\
00(00 \%)\end{array}$ & $\begin{array}{c}23(35.4 \%) \\
42(64.9)\end{array}$ & 146.00 & 0.001 \\
\hline No. of falls (n) & $\begin{array}{l}0 \\
1 \\
2 \\
3 \\
4\end{array}$ & $\begin{array}{c}190(100 \%) \\
- \\
- \\
-\end{array}$ & $\begin{array}{c}00(0 \%) \\
29(44.61 \%) \\
13(20 \%) \\
13(20 \%) \\
10(15.6 \%)\end{array}$ & 255.00 & 0.001 \\
\hline
\end{tabular}

\footnotetext{
*Body structure and function; ${ }^{\circ}$ activity domain; ${ }^{*}$ environmental factors.
} 
ications) of ICF. The analysis for subjects with one fall and more than one fall showed that there was a association of fall with body function and structure domain (GDS score, no. of co morbidities, chronic pain), activity domain (TUG, BBS, EFST) and environmental factors (antihypertensives, NSAIDS and antidepressants) of ICF. The findings of the study is in accordance with results of previous studies on use of ICF for fall risk assessment. ${ }^{14,26,27}$

Sheehan et al. have reported that increased BMI reduced the chances of falls and this is in accordance with our findings. The people with higher BMI might have shown less chance of falls, because their mobility might have reduced. ${ }^{28}$ Excessive body weight have shown to cause reduced mobility and being physically active individuals are more likely for falls. ${ }^{1}$ Where as in recurrent falls, BMI was not a significant risk factor in our current study. The hand grip had shown as a feasible method for identifying falls and it is also reported that hand grip strength may be a general indicator of body strength and the reduced muscle strength is a predictor for falls. ${ }^{29,30}$ The depression and co morbidities have shown an association with falls. The falls tend to increase as there is more comorbidities and it is reported that medical illness is more important than medications in predicting falls. ${ }^{31-33}$

The people with reduced mobility has shown increased risk of falls, people with increased TUG scores are at more risk of falls. ${ }^{22}$ This is a paradoxical finding when it is observed that people with increased BMI are at less risk of falls which might be explained by the mechanism of reduced mobility but reduced mobility itself is a risk factor for more disability in the older adults. The functional mobility impairment has shown to be a risk factor for one time fall and recurrent falls. The reduction in balance scores such as BBS scores has shown to be a important predictor of falls in elderly. ${ }^{24}$ So it is important that optimal level of mobility should be maintained and at the same the older people who are more physically active should be sensitized for falls. The self-report of balance problems, and reduced performance scores in balance tests are associated with increased risk for any fall in community-dwelling older adults who are high func-

Table 2. Comparison of type of comorbidity and medicines between subjects with no fall and one or more falls.

\begin{tabular}{|c|c|c|c|c|}
\hline Type of comorbidity/medicines & $\begin{array}{c}\text { No fall }(\mathrm{N}=190) \\
(\mathrm{M}=100 ; \mathrm{F}=90) \\
\text { Mean+SD/no. }(\%)\end{array}$ & $\begin{array}{c}\text { One or more falls }(\mathrm{N}=65) \\
(\mathrm{M}=32 ; \mathrm{F}=33) \\
\text { Mean+SD/no. }(\%)\end{array}$ & $t / x^{2}$ & $\mathbf{P}$ \\
\hline Diabetes & 96 & 43 & 4.77 & 0.02 \\
\hline Hypertension & 112 & 35 & .005 & 0.94 \\
\hline Chronic pain & 24 & 38 & 55.27 & 0.001 \\
\hline Lower extremity arthritis & 88 & 37 & 2.18 & 0.14 \\
\hline Hypoglycemics & 89 & 42 & 6.67 & 0.03 \\
\hline NSAIDS & 64 & 32 & 4.06 & 0.04 \\
\hline Antidepressants & 35 & 14 & 0.03 & 0.58 \\
\hline Antihypertensives & 80 & 27 & 3.29 & 0.06 \\
\hline
\end{tabular}

Table 3. Fall risks odds ratio for subjects with subjects with no fall and one or more falls.

\begin{tabular}{|c|c|c|c|c|c|c|}
\hline \multirow[t]{2}{*}{ Variable } & \multicolumn{3}{|c|}{ Unadjusted } & \multicolumn{3}{|c|}{ Adjusted } \\
\hline & OR & $95 \% \mathrm{CI}$ & $\mathbf{P}$ & OR & $95 \% \mathrm{CI}$ & $\mathbf{P}$ \\
\hline BMI* & 0.83 & $0.75-0.91$ & 0.001 & 0.83 & $0.75-0.92$ & 0.001 \\
\hline Depression (GDS-S)* & 1.60 & $1.18-2.17$ & 0.001 & 1.45 & $1.06-1.98$ & 0.001 \\
\hline Grip $(\mathrm{kg})^{*}$ & 0.55 & $0.46-0.65$ & 0.001 & 0.54 & $0.45-0.64$ & 0.001 \\
\hline Co morbidities (n)* & 2.20 & $1.63-2.98$ & 0.001 & 2.55 & $1.82-3.57$ & 0.001 \\
\hline Diabetes* & 0.619 & $0.34-1.11$ & 0.10 & 0.45 & $0.24-0.86$ & 0.01 \\
\hline Hypertension* & 1.02 & $0.57-1.80$ & 0.94 & 1.08 & $0.60-1.95$ & 0.05 \\
\hline Chronic pain* & 0.10 & $0.05-0.19$ & 0.001 & 0.067 & $0.03-0.14$ & 0.001 \\
\hline Lower extremity arthritis* & 0.65 & $0.37-1.15$ & 0.14 & 0.68 & $0.38-1.21$ & 0.196 \\
\hline $\operatorname{TUG}(s)^{\circ}$ & 1.20 & $1.14-1.27$ & 0.001 & 1.21 & $1.14-1.28$ & 0.001 \\
\hline $\mathrm{BBS}^{\circ}$ & 0.69 & $0.62-0.77$ & 0.001 & 0.65 & $0.58-0.78$ & 0.001 \\
\hline $\mathrm{EFST}^{\circ}$ & 4.81 & $3.32-6.98$ & 0.001 & 6.09 & $3.87-9.57$ & 0.001 \\
\hline Slip/trip & 25.14 & $11.71-54.82$ & 0.001 & 24.63 & $11.05-54.52$ & 0.001 \\
\hline Walking cane ${ }^{\#}$ & 0.23 & $0.08-0.65$ & 0.006 & 0.23 & $0.08-0.65$ & 0.007 \\
\hline Medications (n) ${ }^{\#}$ & 0.94 & $0.50-1.7$ & 0.84 & 0.95 & $0.87-1.87$ & 0.87 \\
\hline Hypoglycemics $^{\#}$ & 1.97 & $1.11-3.49$ & 0.01 & 2.64 & $1.42-4.90$ & 0.002 \\
\hline Antihypertensives ${ }^{\#}$ & 1.81 & $0.94-3.47$ & 0.07 & 2.16 & $1.11-4.32$ & 0.02 \\
\hline NSAIDS" & 0.55 & $0.31-0.98$ & 0.45 & 0.634 & $0.35-1.14$ & 0.12 \\
\hline Antidepressants & 1.21 & $0.60-2.43$ & 0.58 & 0.65 & $0.31-1.35$ & 0.25 \\
\hline
\end{tabular}

*Body structure and function; ${ }^{\circ}$ activity domain; \#environmental factors. 
tioning. But there is a study in which 5 balance tests combined with health and demographic variables was not able to predict falls in community dwelling older adults. ${ }^{34}$

Among the impairments and scales used to predict falls in this study EFST has shown the highest OR when fallers and non fallers (4.81-unadjusted, 6.09-adjusted) were compared and the same was for fallers and recurrent fallers (8.14-unadjusted, 11.84-adjusted) also. The ESFT have two components which specifically assesses the fall component as well as the gait component which have been related with falls in older adults. ${ }^{25}$ Mehraban et al., done a similar study in Australian older women and found that ICF can be used to understand the various risk factors of falls based on health and functioning. ${ }^{35}$

The assessment methods used is very simple and does not require any sophisticated equipments or devices or any special training for the assessor. So the result of the study is very helpful in predicting falls in older adults in those places lack fund and trained people. The main limitations of the study are the study was cross-sectional without follow up, the subjects were recruited OPD of geriatric care unit set up rather than from the community. Future studies may be carried out with different intervention techniques to see changes in fall risk status on ICF framework.

Table 4. Comparison of baseline characteristics between subjects with one fall and more than one fall.

\begin{tabular}{|c|c|c|c|c|c|}
\hline Variable & & $\begin{array}{c}\text { One fall }(\mathrm{N}=29) \\
(\mathrm{M}=16 ; \mathrm{F}=13) \\
\text { Mean+SD/no. }(\%)\end{array}$ & $\begin{array}{l}\text { More than one falls } \\
\qquad \begin{array}{c}\mathrm{N}=36) \\
(\mathrm{M}=16 ; \mathrm{F}=20) \\
\text { Mean+SD/no. }(\%)\end{array}\end{array}$ & $t / x^{2}$ & $\mathbf{P}$ \\
\hline Age (yrs) & & $71.90 \pm 2.24$ & $73.02 \pm 5.34$ & -2.05 & 0.06 \\
\hline BMI* & & $20.46 \pm 2.93$ & $21.04 \pm 1.36$ & -0.89 & 0.33 \\
\hline Grip (kg)* & & $17.53 \pm 2.44$ & $15.05 \pm 1.96$ & 4.55 & 0.001 \\
\hline Depression (GDS-S)* & & $2.45 \pm 0.50$ & $3.19 \pm 1.21$ & -3.34 & 0.02 \\
\hline TUG $(s)^{\circ}$ & & $15.83 \pm 6.93$ & $25.67 \pm 8.22$ & -5.23 & 0.001 \\
\hline BBS** & & $50.52 \pm 5.36$ & $43.75 \pm 6.83$ & 4.47 & 0.001 \\
\hline $\mathrm{EFST}^{\circ}$ & $\begin{array}{l}0 \\
1 \\
2 \\
3\end{array}$ & $\begin{array}{c}2(6.8 \%) \\
15(51.72 \%) \\
11(37.93 \%) \\
1(3.44 \%)\end{array}$ & $\begin{array}{c}1(2.77 \%) \\
2(5.55 \%) \\
18(50.00 \%) \\
15(41.66 \%)\end{array}$ & 53.21 & 0.001 \\
\hline Comorbidities (n)* & $\begin{array}{l}0 \\
1 \\
2 \\
3 \\
4\end{array}$ & $\begin{array}{c}2(6.89 \%) \\
15(51.73 \%) \\
5(17.24 \%) \\
7(24.13 \%) \\
-\end{array}$ & $\begin{array}{c}00(00 \%) \\
2(5.55 \%) \\
8(22.22 \%) \\
14(38.89 \%) \\
12(33.33 \%)\end{array}$ & 33.56 & 0.001 \\
\hline Slip/trip ${ }^{\circ}$ & $\begin{array}{l}0 \\
1\end{array}$ & $\begin{array}{c}11(37.94 \%) \\
18(62.06 \%))\end{array}$ & $\begin{array}{l}13(36.11 \%) \\
23(63.88 \%)\end{array}$ & 0.02 & 0.88 \\
\hline Medications (n) ${ }^{\#}$ & $\begin{array}{l}1 \\
2 \\
\end{array}$ & $\begin{array}{c}24(82.75 \%) \\
5(17.25 \%) \\
\end{array}$ & $\begin{array}{l}23(63.88 \%) \\
13(36.12 \%) \\
\end{array}$ & 2.86 & 0.091 \\
\hline Walking cane $\mathrm{e}^{\#}$ & & $6(20.6 \%)$ & $3(8.3)$ & 2.23 & 0.13 \\
\hline Injury & $\begin{array}{l}0 \\
1\end{array}$ & $\begin{array}{l}10(34.49 \%) \\
19(65.51 \%)\end{array}$ & $\begin{array}{l}13(36.12 \%) \\
23(63.88 \%)\end{array}$ & 0.19 & 0.89 \\
\hline No. of of falls & $\begin{array}{l}1 \\
2 \\
3 \\
4\end{array}$ & $\begin{array}{l}29(100 \%) \\
00(00 \%) \\
00(00 \%) \\
00(00 \%)\end{array}$ & $\begin{array}{c}00(00 \%) \\
13(36.12 \%) \\
13(36.12 \%) \\
10(27.76)\end{array}$ & 255.00 & 0.001 \\
\hline
\end{tabular}

*Body structure and function; ${ }^{\circ}$ activity domain; ${ }^{\sharp}$ environmental factors.

Table 5. Comparison of type of comorbidity and medicines between subjects with one fall and more than one falls.

\begin{tabular}{|c|c|c|c|c|}
\hline Type of comorbidity/medicines & $\begin{array}{l}\text { One fall }(\mathrm{N}=29) \\
(\mathrm{M}=13 ; \mathrm{F}=16)\end{array}$ & $\begin{array}{l}\text { More than one falls } \\
(\mathrm{N}=36)(\mathrm{M}=16 ; \mathrm{F}=20)\end{array}$ & $t / x^{2}$ & $\mathbf{P}$ \\
\hline Diabetes & 16 & 27 & 2.82 & 0.09 \\
\hline Hypertension & 6 & 29 & 30.76 & 0.001 \\
\hline Chronic pain & 10 & 28 & 12.398 & 0.001 \\
\hline Lower extremity arthritis & 10 & 27 & 10.75 & 0.001 \\
\hline Hypoglycemics & 16 & 26 & 2.04 & 0.15 \\
\hline Antihypertensives & 3 & 24 & 4.78 & 0.02 \\
\hline NSAIDS & 8 & 24 & 8.48 & 0.004 \\
\hline Antidepressants & 11 & 3 & 8.32 & 0.004 \\
\hline
\end{tabular}


Table 6. Fall risks odds ratio for subjects with one fall and more than one falls.

\begin{tabular}{|c|c|c|c|c|c|c|}
\hline \multirow[t]{2}{*}{ Variable } & \multicolumn{3}{|c|}{ Unadjusted } & \multicolumn{3}{|c|}{ Adjusted } \\
\hline & OR & $95 \% \mathrm{CI}$ & $\mathbf{P}$ & OR & $95 \%$ CI & $\mathbf{P}$ \\
\hline BMI* & 1.13 & $0.89-1.43$ & 0.29 & 1.21 & $0.91-1.62$ & 0.17 \\
\hline Grip $(\mathrm{kg})^{*}$ & 0.89 & $0.78-1.01$ & 0.08 & 0.94 & $0.79-1.11$ & 0.50 \\
\hline Comorbidities (n)* & 1.33 & $0.85-2.08$ & 0.20 & 3.04 & $1.38-6.69$ & 0.006 \\
\hline Diabetes* & 0.41 & $0.14-1.17$ & 0.09 & 4.34 & $0.313-60.22$ & 0.274 \\
\hline Hypertension* & 0.03 & $0.008-.12$ & 0.001 & 0.05 & $0.007-.395$ & 0.004 \\
\hline Chronic pain* & 0.15 & $0.05-0.45$ & 0.001 & 0.0 .02 & $0.004-.16$ & 0.001 \\
\hline Lower extremity arthritis* & 5.7 & $1.94-16.69$ & 0.002 & 0.03 & $0.003-.46$ & 0.01 \\
\hline $\operatorname{TUG}(\mathrm{s})^{\circ}$ & 1.15 & $1.07-1.24$ & 0.001 & 1.15 & $1.071-1.25$ & 0.001 \\
\hline $\mathrm{BBS}^{\circ}$ & 0.83 & $0.78-0.92$ & 0.001 & 0.80 & $0.71-0.91$ & 0.001 \\
\hline Depression (GDS-S)* & 2.49 & $1.26-4.91$ & 0.08 & 3.93 & $1.40-11.04$ & 0.009 \\
\hline $\mathrm{EFST}^{\circ}$ & 8.14 & $3.27-20.26$ & 0.001 & 11.84 & $3.91-35.88$ & 0.001 \\
\hline Nature and cause ${ }^{\circ}$ & 1.08 & $0.39-2.97$ & 0.88 & 0.48 & $0.14-1.69$ & 0.25 \\
\hline Walking cane $\mathrm{e}^{\#}$ & 3.00 & $0.67-13.27$ & .14 & 3.3 & $0.54-18.98$ & 0.18 \\
\hline Medications (n) & 2.71 & $0.83-8.82$ & 0.09 & 4.21 & $1.17-15.14$ & 0.027 \\
\hline Hypoglycemics ${ }^{\#}$ & 0.473 & $0.16-1.33$ & 0.15 & 4.78 & $0.39-57.66$ & 0.21 \\
\hline Antihypertensives ${ }^{\#}$ & 0.23 & $0.05-0.91$ & 0.03 & 0.58 & $0.12-2.66$ & 0.48 \\
\hline NSAIDS ${ }^{\#}$ & 0.21 & $0.07-0.62$ & .005 & 0.13 & $0.02-0.63$ & 0.01 \\
\hline Antidepressants $^{\#}$ & 6.72 & $1.65-27.25$ & 008 & 5.35 & $1.23-21.40$ & 0.02 \\
\hline
\end{tabular}

*Body structure and function; ${ }^{\circ}$ activity domain; "environmental factors.

\section{Conclusions}

The results of the study showed that body function and structure, activity and environmental factors of ICF are associated with falls. The strongest predictor of a single fall is activity domain (EFST) score and environmental factors (slip/trip) whereas as activity domain (EFST) score is strongest predictor for more than one fall. Hence the ICF can be a model covering various aspects of health for fall risk assessment in community dwelling older adults.

\section{References}

1. WHO. Global report on falls prevention in older age. WHO Technical Meeting on Falls Prevention in Older Age, Victoria, Canada, 2007. Available from: http://www.who.int/ageing/publications/ Accessed: 30 November 2015.

2. Horak FB. Clinical assessment of balance disorders. Gait Posture 1997;6:76-84.

3. Shanthi GS, Krishnaswamy B. Risk factors for falls in elderly. $\mathrm{J}$ Indian Academy of Ger 2005;2:57-60.

4. Campbell AJ, Reinken J, Allan BC, Martinez GS. Falls in old age: a study of frequency and related clinical factors. Age Ageing 1981;10:264-70.
5. Tinetti ME, Speechley M, Ginter SF. Risk factors for falls among elderly persons living in the community. N Engl J Med 1988;319:1701-77.

6. Downton J, Andrews K. Prevalence, characteristics and factors associated with falls among the elderly living at home. Aging (Milano) 1991;3:219-28.

7. Tinetti ME, Liu WL, Claus EB. Predictors and prognosis of inability to get up after falls among elderly persons. JAMA 1993;269:65-70.

8. Rubenstein LZ. Falls in older people: epidemiology, risk factors and strategies for prevention. Age Ageing 2006; 35:ii37-ii41.

9. Stel VS, Smit JH, Pluijm SM, Lips P. Balance and mobility performance as treatable risk factors for recurrent falling in older persons. J Clin Epidemiol 2003; 56:659-68.

10. Muir SW, Berg K, Chesworth B, Speechley M. Use of the Berg balance scale for predicting multiple falls in community-dwelling elderly people: a prospective study. Phys Ther 2008;88: 449-59.

11. Üstün N, Kostanjsek S, Chatterji Rehm J, eds. Measuring Health and Disability: Manual for WHO Disability Assessment Schedule (WHODAS 2.0). Malta: World Health Organization; 2010.

12. World Health Organization. How to use the ICF: A practical manual for using the International Classification of Functioning, Disability and Health (ICF). Exposure draft for comment. Geneva: WHO; October 2013.

13. Cieza A, Ewert $T$, Ustun $T B$, et al. Development of ICF Core Sets for patients with chronic conditions. J Rehabil Med 2004;44:9-11.

14. Huang SW, Lin LF, Chou LC, et al. Feasibility of using the International Classification of Functioning, Disability and Health Core Set for evaluation of fall-related risk factors in acute rehabilitation settings. Eur Journal Phys Rehabili Med 2016;52: 152-8.

15. Panel on Prevention of Falls in Older Persons. American Geriatrics Society, British Geriatrics Society. Summary of the updated American Geriatrics Society/British eriatrics Society clinical practice guideline for prevention of falls in older persons. J Am Geri Soc 2011; 59:148-57.

16. Zecevic AA, Salmoni AW, Speechley Mark, Vandervoort AA. Defining a fall and reasons for falling: comparisons among the views of seniors, health care providers, and the research literature. Gerontologist 2006;46:367-76.

17. Shah NR, Braverman ER. Measuring adiposity in patients: the utility of body mass index (BMI), percent body fat, and leptin. PLoS One 2012;7:e33308. 
18. Fiuutko R. The comparison study of grip strength in male population of Kuwait and Poland. J Spor Med 1987; 27:497-500.

19. Hughes S, Gibbs J, Dunlop D, et al. Predictors of decline in manual performance in older adults. J Am Geri Soc 1997;45:905-10.

20. Sheikh JI, Yesavage JA. Geriatric Depression Scale (GDS): recent evidence and development of a shorter version. Clin Gerontol 1986;5:165-73.

21. Podsiadlo D, Richardson S. The timed" Up \& Go": a test of basic functional mobility for frail elderly persons. J Am Ger Soc 1991;39:142-8.

22. Shumway-Cook A, Brauer S, Woollacott M. "Predicting the probability for falls in community-dwelling older adults using the Timed Up \& Go Test." Phys Ther 2000;80:896-903.

23. Berg KO, Wood-Dauphinee SL, Williams JI, Maki B. Measuring balance in the elderly: validation of an instrument. Can J Pub Health 1992;83: S7-11.

24. Thorbahn LDB, Newton RA. Use of the Berg Balance Test to Predict Falls in Elderly Persons. Phys Ther 1996;76: 576-83.

25. Cwikel JG, Fried AV, Biderman A,
Galinsky D. Validation of a fall-risk screening test, the Elderly Fall Screening Test (EFST), for communitydwelling elderly. Disabil Rehabil1998; 20:161-7.

26. Yen TH, Lin LF, Wei TS, et al. Delphibased assessment of fall-related risk factors in acute rehabilitation settings according to the international classification of functioning, disability and health. Arch Phys Med Rehabil 2014; 95:50-7.

27. Beninato M, Portney LG, Sullivan PE. Using the International Classification of Functioning, Disability and Health as a framework to examine the association between falls and clinical assessment tools in people with stroke. Phys Ther 2009;89:816-25.

28. Sheehan KJ, Cunningham C, Crosby L, Kenny RA. The relationship between increased body mass index and frailty on falls in community dwelling older adults. BMC Geri 2013;1:132.

29. Gunter KB, White KN, Hayes WC, Snow CM. Functional mobility discriminates nonfallers from one-time and frequent fallers. J Gerontol Biol Sci Med Sci 2000;55:M672-6.

30. Taekema DG, Gussekloo J, Maier AB, et al. Handgrip strength as a predictor of functional, psychological and social health. A prospective population-based study among the oldest old. Age Ageing 2010;39:331-7.

31. Biderman A, Cwikel J, Fried AV, Galinsky D. Depression and falls among community dwelling elderly people: a search for common risk factors. J Epid Comm Healt 2002;56:631-6.

32. Tinetti ME, Williams TF, Mayewski R. Fall risk index for elderly patients based on number of chronic disabilities. Am J Med 1986;80:429-32.

33. Lee JS, Kwok T, Leung PC, Woo J. Medical illnesses are more important than medications as risk factors of falls in older community dwellers? A crosssectional study. Age Ageing 2006;353: 246-51.

34. Boulgarides LK, McGinty SM, Willett JA, Barnes CW. Use of clinical and impairment-based tests to predict falls by community-dwelling older adults. Phys Ther 2003;83:328-39.

35. Mehraban AH, Mackenzie L, Byles J, et al. Can the International Classification of Functioning, Disability and Health (ICF) be used to understand risk factors for falls in older Australian women?. Health 2013;5;39-48. 